\title{
BMJ Open Understanding patient profiles and characteristics of current chiropractic practice: a cross-sectional Ontario Chiropractic Observation and Analysis STudy (O-COAST)
}

\author{
Silvano Mior, ${ }^{1,2}$ Jessica Wong, ${ }^{1,2}$ Deborah Sutton, ${ }^{2}$ Peter J H Beliveau, ${ }^{3}$ \\ André Bussières, ${ }^{4,5}$ Sheilah Hogg-Johnson, ${ }^{6,7}$ Simon French $^{8,9}$
}

To cite: Mior S, Wong J, Sutton $\mathrm{D}$, et al. Understanding patient profiles and characteristics of current chiropractic practice: a crosssectional Ontario Chiropractic Observation and Analysis STudy (0-COAST). BMJ Open 2019;9:e029851. doi:10.1136/ bmjopen-2019-029851

- Prepublication history and additional material for this paper are available online. To view these files, please visit the journal online (http://dx.doi org/10.1136/bmjopen-2019029851).

Received 15 February 2019 Revised 17 June 2019 Accepted 30 July 2019

Check for updates

(C) Author(s) (or their employer(s)) 2019. Re-use permitted under CC BY-NC. No commercial re-use. See rights and permissions. Published by BMJ.

For numbered affiliations see end of article.

Correspondence to

Dr Silvano Mior;

SMior@cmcc.ca

\section{ABSTRACT}

Objectives There is no current detailed profile of people seeking chiropractic care in Canada. We describe the profiles of chiropractors' practice and the reasons, nature of the care provided to their patients and extent of interprofessional collaborations in Ontario, Canada.

Design Cross-sectional observational study.

Setting Primary care setting in Ontario, Canada.

Participants We randomly recruited chiropractors from a list of registered chiropractors $(\mathrm{n}=3978)$ in active practice in 2015. Of the 135 randomly selected chiropractors, 120 were eligible, 43 participated and 42 completed the study. Outcome measures Each chiropractor recorded information for up to 100 consecutive patient encounters, documenting patient health profiles, reasons for encounter, diagnoses and care provided. Descriptive statistics summarised chiropractor, patient and encounter characteristics, with analyses accounting for clustering and design effects.

Results Chiropractors provided data on 3523 chiropractor-patient encounters. More than $65 \%$ of participating chiropractors were male, mean age 44 years and had practised on average 15 years. The typical patient was female ( $59 \%$ of encounters), between 45 and 64 years $(43 \%)$ and retired $(21 \%)$ or employed in business and administration (13\%). Most (39.4\%) referrals were from other patients, with $6.8 \%$ from physicians. Approximately $68 \%$ of patients paid out of pocket or claimed extended health insurance for care. Most common diagnoses were back ( $49 \%, 95 \% \mathrm{Cl} 44$ to 56 ) and neck $(15 \%, 95 \% \mathrm{Cl} 13$ to 18$)$ problems, with few encounters related to maintenance/preventive care $(0.86 \%, 95 \% \mathrm{Cl}$ 0.2 to 3.9$)$ and non-musculoskeletal problems $(1.3 \%$, $95 \% \mathrm{Cl} 0.7$ to 2.3). The most common treatments included spinal manipulation $(72 \%)$, soft tissue therapy $(70 \%)$ and mobilisation $(35 \%)$.

Conclusions This is the most comprehensive profile to date of chiropractic practice in Canada. People who present to Ontario chiropractors are mostly adults with a musculoskeletal condition. Our results can be used by stakeholders to make informed decisions about workforce development, education and healthcare policy related to chiropractic care.

\section{Strengths and limitations of this study}

- Cross-sectional study with data collected prospectively, employing a method of recording patient encounters with demonstrated reliability and validity in primary care settings

- We adjusted for clustering effects of patients presenting to the same chiropractor in the analysis.

- We had a $36 \%$ response rate, higher than previously reported in similar studies; however, results may not be generalisable to all chiropractors in Ontario.

- The coding of reasons for encounter and diagnoses required judgement from the coder; however, we minimised this subjectivity by using an established coding system and employing a quality assurance protocol across the two coders.

\section{INTRODUCTION}

Chiropractors practice in $>100$ countries, with the largest distribution practising in the USA and Canada. ${ }^{1}$ The most common reported reasons for people attending chiropractic care worldwide are (median, IQR of chiropractic encounters) low back pain $(49.7 \%$, IQR: $43.0 \%-60.2 \%)$, neck pain $(22.5 \%$, IQR: $16.3 \%-24.5 \%)$ and extremity problems $(10.0 \%$, IQR: $4.3 \%-22.0 \%)$. Only $3.1 \%$ (IQR: $1.6 \%-6.1 \%$ ) of the general population sought chiropractic care for non-musculoskeletal conditions. ${ }^{2}$ The majority of patients seeing a chiropractor received spinal manipulative therapy, in addition to soft tissue therapy, exercise and education. ${ }^{23}$ However, most available information from chiropractic clinical practice informs utilisation rates, with only sparse data describing patient profiles of chiropractic practice in Canada. ${ }^{245}$

In 2016 , there were $>4300$ chiropractors practising in various regions of Ontario, Canada, with the majority located in the 
Greater Toronto Area. ${ }^{167}$ Annually in Ontario, chiropractors provide care to $11 \%$ of the population, and to about a third of those people in the population who report chronic low back pain. ${ }^{4}$ Approximately one-third of chiropractic patients in Ontario are between 35 and 50 years of age and about two-thirds have chronic or recurrent pain. ${ }^{5}$ Chiropractors commonly treat people for disorders of the low back and neck, and patients receive a mean of 8.6 chiropractic visits. ${ }^{5}$ However, these findings require updating (ie, data collected prior to 2001) and may not reflect current chiropractic practice in Canada.

French et al conducted a cross-sectional observational study to describe chiropractic practice in Australia. ${ }^{8}$ The Chiropractic Observation and Analysis STudy (COAST) was modelled on the Bettering the Evaluation and Care of Health (BEACH) method..$^{9}$ BEACH methods are well established and the data widely cited; BEACH data are used by the general medical profession, government, researchers and industry, and has significantly impacted primary care policy and practice in Australia. ${ }^{10}$ Utilising similar methods to collect data in Canada could inform current chiropractic practice patterns and trends, and help guide healthcare human resource planning, education and policy.

The purpose of this study was to describe the practices of chiropractors and chiropractic patient profiles in Ontario, Canada. Specifically, we aimed to describe the: (1) demographic characteristics of chiropractors in Ontario, (2) characteristics (demographic and health profile) of the people who seek chiropractic care, (3) reasons people seek chiropractic care (reasons for encounter), (4) care chiropractors provide and (5) the nature of collaborations between chiropractors and other healthcare providers.

\section{METHODS}

We used a cross-sectional observational study design to define chiropractic practice in Ontario, Canada.

\section{Recruitment}

We used a modified tailored design method for recruitment based on BEACH and COAST methods. ${ }^{81112} \mathrm{BEACH}$ investigators determined that a minimum sample of 40 healthcare practitioners is required to ensure reasonable precision for more frequent events. ${ }^{13}$ We aimed to have 45 chiropractors complete the study. We randomly selected 135 chiropractors from the list of 3978 chiropractors registered with the College of Chiropractors of Ontario in the 2014 directory (figure 1). Chiropractors in active clinical practice in Ontario, Canada (full-time, part-time or locum) were eligible to participate.

We commenced recruitment of chiropractors in June 2014. We raised study awareness through articles and advertisements in the newsletters of the Ontario Chiropractic Association (OCA) and the Canadian Chiropractic Association (CCA). The randomly selected chiropractors were sent an introductory letter, followed by an invitation letter and reminder letters after 1 and 3 weeks. Non-responders were contacted by telephone 4 weeks later. Participants were offered continuing education hours to compensate for their time related to participation.

Each chiropractor invited consecutive patients to participate until 100 patient encounters were recorded per chiropractor, or when 4 weeks of recording had elapsed. Each encounter provided a snapshot in time of the participating chiropractors' clinic activity. With chiropractors recruited through random selection, each encounter can be considered a randomly selected encounter from all those occurring in Ontario at that time. Some of the encounters were new patient visits, and some were repeat visits, depending on the make up the participating chiropractor's practice profile. The selection of 100 encounters or maximum 4-week time period was what we considered most feasible for chiropractors to participate, based on our experience in the Australian COAST study ${ }^{8}$ and the experience of the investigators in the well-established BEACH study. ${ }^{9}$ Participating chiropractors obtained patient consent to have their deidentified information collected.

\section{Data collection}

The encounter recording form was based on BEACH ${ }^{11}$ and $\mathrm{COAST}^{8}$ studies and has established reliability and validity in primary care. ${ }^{14}$ Modifications were made with input from the Study Advisory Committee (with representatives from the OCA, CCA and CMCC). Item modifications were made to reflect practice in Ontario and included payment methods, classification of occupation and general health and lifestyle questions; the data collection form is available on request. The modified forms were first piloted by five chiropractors with varying practice styles who each collected data on 10 consecutive patients. Minor changes were made to the format of the forms based on feedback from pilot testing.

Participating chiropractors were trained in completing the forms and recorded patient encounter data by hand on paper recording forms, with items in free text or check box formats. Each participating chiropractor was provided with a note pad of 110 forms, with extra forms included to allow for errors (see online supplementary file 1 for items collected).

\section{Data coding and quality assurance}

A detailed explanation of data coding, the process for generating new terms, and subsequent coding and grouping system has been previously published..$^{15}$ Briefly, chiropractors recorded the reasons for encounter and diagnoses for up to three problems treated during each patient encounter. Each description was subsequently classified by a trained coder (researcher and chiropractor) according to the International Classification of Primary Care, 2nd edition (ICPC-2), using the Australian ICPC-2 PLUS general practice terminology. ${ }^{16}$ We also coded to terms that were specific to the chiropractic profession. ${ }^{15}$ For example, we included wellness-related terms that 


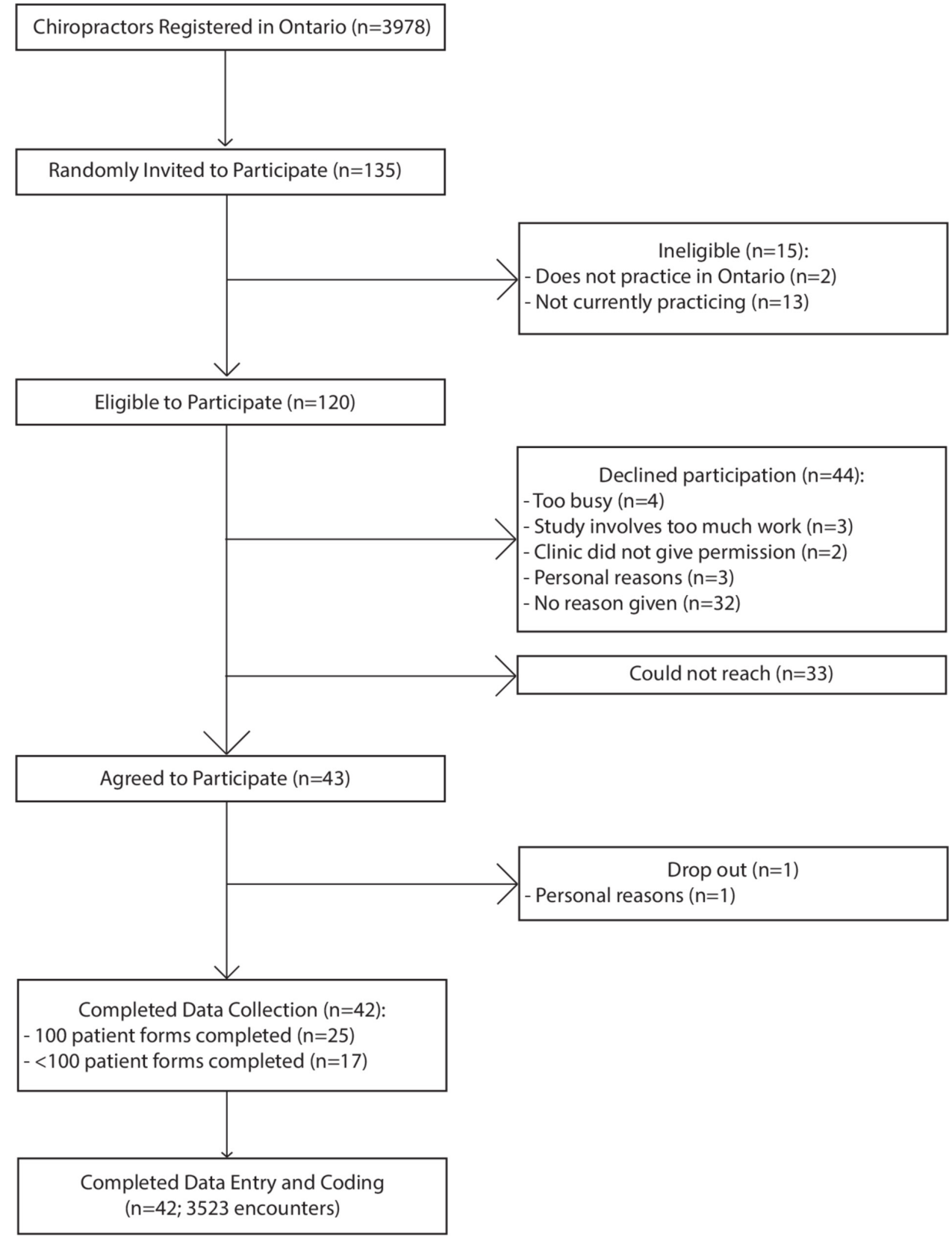

Figure 1 Flow diagram for the enrolment of chiropractors and data collection for the Ontario Chiropractic Observation and Analysis STudy.

described patients with little or no symptoms (eg, health maintenance, check-up). Where a reason for encounter or diagnosis was documented with no corresponding ICPC-2 PLUS term, a new term (and code) was created.

Data were entered into a Microsoft Access database linked to the coding and ICPC-2 classification system. Reliability of data entry was assured by: (1) computer-aided error checks ('locks') in the Microsoft Access database at the data entry stage; and (2) a physical check of data entered on one randomly selected recording form per chiropractor participant by two trained independent coders. The two independent coders checked for agreement with the original data entered at the level of the ICPC-2 PLUS chapter/group. In the event of a disagreement, another team member reviewed the coding to reach consensus.

\section{Data analysis}

We used descriptive statistics to summarise chiropractor, patient and encounter characteristics. We reported reasons for encounter by ICPC chapter, and reported chiropractor-identified problems and diagnoses by groups of related ICPC-2 PLUS terms. For each chiropractor, patients attending more than once during the 100 encounters recorded were identified by date of birth, sex and postal code, in order to provide unique patient information. We calculated point estimates of proportions or rates, as applicable, and 95\% CIs. All analyses 
accounted for the clustered nature of the design with encounters nested within chiropractors using the Survey features in STATA (svy prefix command). Data preparation and management were conducted using SAS (20022012). We derived point estimates and $95 \%$ CIs using STATA V.10.1.

\section{RESULTS}

We approached 135 randomly selected chiropractors (figure 1). Of these, 120 chiropractors were eligible, and 43 agreed to participate ( $36 \%$ response rate); one chiropractor withdrew and did not provide any data; thus 42 $(35 \%)$ completed the study. Of the non-participants, 15 were ineligible and 44 declined to participate (figure 1); we were unable to collect specific information that would allow us to compare characteristics of participants and non-participants.

Participating chiropractors provided information on 3523 chiropractor-patient encounters between 3 July 2014 and 15 July 2015 . Not all chiropractors provided information on 100 encounters; 25 provided information on at least 100, and 17 provided information on an average of 57 encounters (range 14-95).

\section{Chiropractor characteristics}

Two-thirds of the chiropractor participants were male (table 1). The mean age of respondents was 44 years old with an average of 15 years in practice. The majority of respondents graduated from a chiropractic college in Canada $(81 \%)$. Half of chiropractor participants were in solo practice, with a majority $(81 \%)$ reporting a general or family style of chiropractic practice. There were $76 \%$ and $12 \%$ of respondents reporting other non-chiropractic practitioners or imaging services available at the same clinic, respectively.

\section{Patient characteristics}

The majority of unique patients were females (59\%) between the ages of 45 and 64 years (table 2). Patients were younger than 15 years old in $5.5 \%$ of encounters and aged 65 years and older in $18.8 \%$ of encounters. About $4 \%$ of patients had a non-English speaking background or self-identified as Indigenous. About $65 \%$ of patients reported that their reason for encounter $(n=3979)$ was for musculoskeletal problems, $22.6 \%$ was for general or unspecified problems, $7.5 \%$ for neurologically related problems and $4.8 \%$ for non-musculoskeletal problems (eg, digestive, ear, eye, respiratory, skin, urology, circulatory, endocrine and metabolic, psychological). Patients paid for some, or all, of the consultation fee in $68 \%$ (95\% CI $60 \%$ to $77 \%$ ) of encounters.

Most patients (53.5\%) reported being in excellent/very good overall health and enjoying life. Almost $90 \%$ rated their quality of life as excellent/very good and almost three-quarters were satisfied with their health. About a quarter of patients reported that their level of activity was a great deal or extremely limited because of pain. Online
Table 1 Characteristics of chiropractors participating in Ontario Chiropractic Observation and Analysis STudy $(n=42)$

\begin{tabular}{|c|c|}
\hline Characteristics & Chiropractors* $^{\star}$ \\
\hline \multicolumn{2}{|l|}{ Chiropractor characteristics } \\
\hline Mean age in years (range; SD) & $44(25-71 ; 11.4)$ \\
\hline Mean years in practice (range; SD) & $15(2-45 ; 11.0)$ \\
\hline Years since graduation (range; SD) & $17(3-45 ; 11.1)$ \\
\hline Female & $14(33 \%)$ \\
\hline \multicolumn{2}{|l|}{ Country of graduation } \\
\hline Canada & $34(81 \%)$ \\
\hline USA & $7(17 \%)$ \\
\hline Australia & $1(2 \%)$ \\
\hline Holds postgraduate qualification & $7(18 \%)$ \\
\hline \multicolumn{2}{|l|}{ Practice characteristics } \\
\hline $\begin{array}{l}\text { Mean number of patient visits per week } \\
\text { (range; SD) }\end{array}$ & $100(5-250 ; 78.1)$ \\
\hline Solo practitioner & $21(50 \%)$ \\
\hline Other chiropractor(s) at practice & $21(50 \%)$ \\
\hline $\begin{array}{l}\text { Other non-chiropractic healthcare } \\
\text { practitioner available at same premises }\end{array}$ & $32(76 \%)$ \\
\hline $\begin{array}{l}\text { Imaging services available at same } \\
\text { premises }\end{array}$ & $5(12 \%)$ \\
\hline Paper-only clinical records & $22(52 \%)$ \\
\hline \multicolumn{2}{|l|}{ Type of practice } \\
\hline General/family & $34(81 \%)$ \\
\hline Sports/rehabilitation & $6(14 \%)$ \\
\hline Wellness/lifestyle counselling & $2(4 \%)$ \\
\hline
\end{tabular}

${ }^{*}$ No of chiropractors, unless otherwise indicated.

supplementary file 2 summarises patient-reported quality of life measures.

\section{Referrals and collaboration with other healthcare providers}

Patients were most commonly referred from other patients (39.4\% of encounters), other sources (eg, internet, friends, family; $12.9 \%$ of encounters). Patients were referred from a family physician in $6.8 \%$ of encounters. Chiropractors referred patients to other healthcare providers in $<3 \%$ of encounters (family physician 2.2\%, other complementary and alternative providers $0.8 \%$ ). Although only occurring in very few encounters, in addition to seeing the chiropractor, patients saw kinesiologists (4\% of encounters), massage therapists (1\% of encounters) and physiotherapists $(0.3 \%$ of encounters) during the chiropractor-patient encounter.

\section{Problems and treatments provided}

The most common problems reported by the chiropractors were for back (49\%, 95\% CI 44 to 56) and neck disorders $(15 \%, 95 \%$ CI 13 to 18$)$, followed by back and leg pain $(6 \%, 95 \%$ CI 5 to 8$)$ (table 3). Back and neck problems included chiropractor-recorded terms such as 'chiropractic subluxation', used in $33.6 \%$ (95\% CI $22.2 \%$ to $47.3 \%$ ) of 
Table 2 Characteristics of unique patients in encounters as recorded by participating chiropractors*

\begin{tabular}{|c|c|c|}
\hline Patient characteristics & $\mathrm{n}=2423$ & $\%$ \\
\hline Sex: female & 1426 & 58.85 \\
\hline \multicolumn{3}{|l|}{ Age (in years) } \\
\hline$<1$ & 30 & 1.26 \\
\hline $1-4$ & 12 & 0.50 \\
\hline $5-14$ & 88 & 3.70 \\
\hline $15-24$ & 177 & 7.44 \\
\hline $25-44$ & 634 & 26.64 \\
\hline $45-64$ & 991 & 41.64 \\
\hline $65-74$ & 296 & 12.44 \\
\hline$\geq 75$ & 152 & 6.39 \\
\hline \multicolumn{3}{|l|}{ Language } \\
\hline Non-English speaking background & 92 & 3.86 \\
\hline Identifies as Aboriginal/Indigenous & 2 & 0.08 \\
\hline \multicolumn{3}{|l|}{ Occupations $†$} \\
\hline Management/administration $\ddagger$ & 424 & 17.50 \\
\hline Health/applied sciences§ & 217 & 8.96 \\
\hline $\begin{array}{l}\text { Education, social, government } \\
\text { services } \|\end{array}$ & 292 & 12.05 \\
\hline $\begin{array}{l}\text { Sales/trades/manufacturing/ } \\
\text { agriculture }^{\star \star}\end{array}$ & 480 & 19.81 \\
\hline Home duties & 104 & 4.29 \\
\hline Retired & 473 & 19.52 \\
\hline Student & 206 & 8.50 \\
\hline Unemployed/non-employed & 17 & 0.70 \\
\hline \multicolumn{3}{|l|}{ Source of encounter payment } \\
\hline $\begin{array}{l}\text { Workplace safety and insurance } \\
\text { board }\end{array}$ & 20 & 0.84 \\
\hline Motor vehicle accident & 98 & 4.12 \\
\hline Veterans affairs & 9 & 0.38 \\
\hline Extended private health insurance & 732 & 30.76 \\
\hline Patient paid & 1627 & 68.36 \\
\hline No charge & 60 & 2.52 \\
\hline
\end{tabular}

${ }^{\star}$ Represents first encounter per patient and missing values not used in calculations.

†Missing data $(\mathrm{n}=210)$ not included.

¥Occupations: management, business, finance and administration.

§Health, natural and applied sciences and related

ПEducation, law and social, community and government services, art, culture, recreation and sport

${ }^{*}$ Sales and services; trades, transports and equipment and related; natural resources, agriculture and related opportunities; manufacturing and utilies.

encounters, to describe a dysfunction detected in a joint segment. ${ }^{17}$ There were very few encounters related to maintenance/preventive care $(0.86 \%, 95 \%$ CI 0.2 to 3.9$)$ and non-musculoskeletal problems $(1.3 \%, 95 \%$ CI 0.7 to 2.3$)$.

Manual adjustment was provided in 72 per 100 encounters and comprised almost a quarter of all techniques and care provided (table 4). Soft tissue therapy was provided about twice as often as mobilisation methods. Passive modalities (eg, laser, ultrasound) were less frequently used, and therapeutic exercise was recorded in only about 3.5 per 100 encounters.

\section{DISCUSSION}

This is the first comprehensive profiling of chiropractic practice undertaken in Canada using BEACH methods to describe who seeks chiropractic care, why they sought care, the diagnoses/problems chiropractors identified and the care chiropractors provided. People who present to Ontario chiropractors are mostly adults with a musculoskeletal condition, notably back pain. The most frequent care provided by the chiropractors was spinal manipulation and soft tissue therapy. Patients were most commonly referred from other patients and few by a family physician, while chiropractors reported to rarely refer to other healthcare providers.

The demographics of chiropractors and their practice characteristics who participated in our study are similar to chiropractors worldwide. ${ }^{2}$ Chiropractors manage a range of conditions, but as noted in previous studies, ${ }^{451819}$ the vast majority of conditions seen by chiropractors reflect a musculoskeletal origin. Back and neck pain are the predominant specific conditions managed, again consistent with previous work. ${ }^{2351819}$

Most patients reported excellent to good health and quality of life, but their physical activities were moderately to extremely limited by their pain. Few encounters were specifically associated with wellness or maintenance and non-musculoskeletal care. Some chiropractors consider wellness or maintenance care an integral component of chiropractic care despite inconsistency in definition and limited evidence of effectiveness. ${ }^{20}{ }^{21}$ However, a recent pragmatic trial suggested that for select patients with recurrent or persistent non-specific low back pain who reportedly responded well to an initial course of chiropractic care, maintenance care may be considered as an option for tertiary prevention. ${ }^{22}$ In this trial, maintenance care was more effective than symptom-guided care in reducing the total number of days with bothersome non-specific low back pain over 1 year. ${ }^{22}$ However, the delivery and rationale for wellness and maintenance care continues to be an area of ongoing debate within the profession and requires continued research. ${ }^{102123}$ Our study findings suggest that a small percentage of chiropractors in Ontario provide wellness or maintenance care to patients.

Similar to other studies, ${ }^{24}$ our findings suggest that manual adjustments and soft tissue therapy are provided in up to $90 \%$ of chiropractic visits. The distribution of spinal manipulative therapy, soft tissue therapy and other techniques are similar to those previously reported. ${ }^{525}$ However, we found few reported instances where therapeutic exercises were provided. It is unclear whether this result was related to the design of the data collection form, as it did not include a prompt for reporting exercise. We 
Table 3 Distribution of most frequent problems managed as reported by chiropractors ${ }^{\star}$

\begin{tabular}{|c|c|c|c|}
\hline & \multirow[b]{2}{*}{ Number } & \multirow{2}{*}{$\begin{array}{l}\text { Percent of total problems } \\
\text { managed }(n=4540)\end{array}$} & \multirow{2}{*}{$\begin{array}{l}\begin{array}{l}\text { Estimate per } 100 \text { encounters } \\
(\mathrm{n}=3523)\end{array} \\
\text { Estimate }(95 \% \mathrm{Cl})\end{array}$} \\
\hline & & & \\
\hline Back problem & 2242 & 49.38 (43.3 to 55.5 ) & 63.64 (55.7 to 70.9$)$ \\
\hline Neck problem & 689 & $15.18(12.5$ to 18.3$)$ & 19.56 (15.6 to 24.3 ) \\
\hline Back syndrome with radiating pain & 273 & 6.01 (4.5 to 8.0$)$ & 7.75 (5.7 to 10.5$)$ \\
\hline Sprain/strain of joint nos & 194 & 4.27 (3.2 to 5.8$)$ & $5.51(4.1$ to 7.4$)$ \\
\hline Bursitis/tendinitis nos & 148 & 3.26 (2.1 to 5.0$)$ & $4.20(2.7$ to 6.5$)$ \\
\hline Shoulder problem & 121 & 2.67 (1.9 to 3.7 ) & $3.43(2.4$ to 4.8$)$ \\
\hline Muscle problem & 95 & 2.09 (1.4 to 3.1$)$ & 2.70 (1.8 to 4.1$)$ \\
\hline Osteoarthritis, other (not spine) & 89 & $1.96(1.4$ to 2.7$)$ & 2.53 (1.8 to 3.5$)$ \\
\hline Non-musculoskeletal problem & 57 & $1.28(0.7$ to 2.3$)$ & 1.59 (0.9 to 2.8$)$ \\
\hline Musculoskeletal disease, other & 44 & $0.97(0.5$ to 1.9$)$ & 1.25 (0.7 to 2.4$)$ \\
\hline Neurological problem & 42 & 0.93 (0.5 to 1.8$)$ & 1.19 (0.6 to 2.3$)$ \\
\hline Hip symptom/complaint & 42 & $0.93(0.5$ to 1.6$)$ & $1.19(0.7$ to 2.1$)$ \\
\hline Musculoskeletal symptom/complaint other & 42 & 0.93 (0.4 to 1.4$)$ & 1.19 (0.5 to 2.9$)$ \\
\hline Health maintenance/preventive care & 39 & $0.86(0.2$ to 3.9$)$ & $1.11(0.2$ to 5.0$)$ \\
\hline Kyphosis and scoliosis & 36 & 0.79 (0.3 to 2.1$)$ & 1.02 (0.4 to 2.7$)$ \\
\hline Knee symptom/complaint & 35 & 0.77 (0.4 to 1.4$)$ & 0.99 (0.6 to 1.7$)$ \\
\hline Ankle problem & 32 & 0.70 (0.4 to 1.2$)$ & 0.91 (0.5 to 1.5$)$ \\
\hline Headache & 31 & 0.68 (0.3 to 1.4$)$ & 0.88 (0.4 to 1.8$)$ \\
\hline Tennis elbow & 28 & 0.62 (0.3 to 1.3$)$ & 0.79 (0.4 to 1.7$)$ \\
\hline Jaw symptom/complaint & 26 & 0.57 (0.4 to 0.9$)$ & 0.74 (0.5 to 1.1$)$ \\
\hline Injury musculoskeletal nos & 22 & 0.48 (0.2 to 1.0$)$ & 0.62 (0.3 to 1.3$)$ \\
\hline Concussion & 22 & $0.48(0.2$ to 1.3$)$ & $0.62(0.2$ to 1.7$)$ \\
\hline
\end{tabular}

*Missing data not used in calculations.

nos, not otherwise specified.

also found few reported instances where passive physical/ electromodalities were provided. The reported use of interventions has important implications regarding the implementation of evidence-based clinical guidelines. These guidelines indicate weak to moderate evidence for the use of manipulation or mobilisation and exercises in neck ${ }^{26} 27$ and low back pain, ${ }^{28} 29$ but little evidence supporting the therapeutic efficacy for other manual therapeutic interventions, such as mechanical manipulative devices. ${ }^{30} 31$ Awareness of such knowledge-to-practice gaps provide guidance for developing and implementing targeted knowledge translation strategies to facilitate uptake and application of guideline recommendations in clinical practice.

Chiropractors do not appear to regularly communicate with or refer to other healthcare providers during the encounter. While patients are the most common source of referral to chiropractors, chiropractors refer patients to other healthcare providers $<3 \%$ of the time. This low referral rate may also relate to the majority of patients reporting to be in excellent and very good health. Less than $4 \%$ of encounters involved patients seeing other healthcare providers or involved chiropractors communicating with other healthcare providers. It may be that chiropractors communicate with other healthcare providers outside of the encounter. Nevertheless, our findings suggest there are opportunities for enhancing collaboration between chiropractors and other healthcare providers. Improving interprofessional communication and collaboration will facilitate continuity of care ${ }^{32}$ Future research to examine indications and effective strategies for interprofessional collaboration among chiropractors and other healthcare providers, including family physicians, is warranted.

Our findings suggest that most patients $(68 \%)$ pay out-of-pocket for their treatments, though it is unclear how many then submit to extended health insurance for reimbursement. Approximately $31 \%$ and $1 \%$ of encounters were paid by extended health insurance directly and WSIB, respectively. These proportions of source of payment are similar to those reported by OCA members in 2010 , where $60 \%, 30 \%$ and $5 \%$ were attributed to patient paying out-of-pocket, extended 
Table 4 Distribution of techniques and care provided

\begin{tabular}{|c|c|c|c|}
\hline & & $\begin{array}{l}\text { Percent of total techniques and } \\
\text { care provided }(n=11223)^{\star}\end{array}$ & $\begin{array}{l}\text { Estimate per } 100 \text { encounters } \\
(n=3523)\end{array}$ \\
\hline Techniques and care provided & Number & $\%(95 \% \mathrm{Cl})$ & $\%(95 \% \mathrm{Cl})$ \\
\hline Manual adjustment & 2545 & 22.7 (19.2 to 26.6) & 72.2 (60.1 to 86.9$)$ \\
\hline Soft tissue therapy & 2481 & 22.1 (18.3 to 26.5$)$ & 70.4 (56.3 to 88.1$)$ \\
\hline Mobilisation & 1223 & 10.9 (7.7 to 15.2$)$ & 34.7 (23.1 to 52.1$)$ \\
\hline Activator & 1053 & 9.4 (5.3 to 16.2$)$ & 29.9 (18.3 to 48.8$)$ \\
\hline Chiropractic system & 706 & $6.3(2.0$ to 18.3$)$ & 20 (18.3 to 48.8 ) \\
\hline Drop piece technique & 702 & 6.3 (3.6 to 10.7 ) & 19.9 (11.1 to 35.8$)$ \\
\hline Laser & 338 & $3.0(1.4$ to 6.4$)$ & 9.6 (4.3 to 21.2$)$ \\
\hline Acupuncture & 304 & $2.7(1.4$ to 5.1$)$ & 8.6 (4.6 to 16.1$)$ \\
\hline Ultrasound & 302 & $2.7(1.1$ to 6.6$)$ & 8.6 (3.2 to 22.7 ) \\
\hline Flexion distraction & 295 & $2.6(0.6$ to 10.3$)$ & 8.4 (1.9 to 36.9$)$ \\
\hline Interferential therapy & 285 & 2.5 (1.3 to 5.0$)$ & 8.1 (3.9 to 16.9$)$ \\
\hline Electrical stimulation & 226 & 2.0 (0.6 to 6.3$)$ & $6.4(2.1$ to 20.1$)$ \\
\hline Heat therapy & 219 & 1.9 (0.9 to 4.2$)$ & $6.2(2.8$ to 13.8$)$ \\
\hline Traction (technique) & 148 & $1.3(0.5$ to 3.5$)$ & $4.2(1.5$ to 11.6$)$ \\
\hline Therapeutic exercises & 123 & $1.1(0.5$ to 2.3$)$ & 3.5 (1.5 to 8.0$)$ \\
\hline Thumper (massager) & 119 & $1.1(0.5$ to 2.4$)$ & $3.4(1.4$ to 7.9$)$ \\
\hline Ice pack & 34 & $0.3(0.1$ to 1.0$)$ & 1.0 (0.3 to 3.3$)$ \\
\hline TENS & 31 & 0.3 (0.05 to 1.4$)$ & 0.9 (0.2 to 4.4$)$ \\
\hline Massage & 15 & 0.1 (0.02 to 0.1$)$ & 0.4 (0.1 to 3.3 ) \\
\hline Blocks & 14 & 0.1 (0.05 to 0.3 ) & $0.4(0.2$ to 1.0$)$ \\
\hline Orthotic fitting & 12 & 0.1 (0.04 to 0.3 ) & 0.3 (0.1 to 0.8 ) \\
\hline
\end{tabular}

*Missing data not used in calculations.

TENS, transcutaneous electrical nerve stimulation.

health insurance and WSIB, respectively ( $\mathrm{R}$ Haig, personal communication, 2015).

Musculoskeletal conditions, and in particular low back and neck pain, are the world's leading causes of disability, and present a major societal and individual burden. ${ }^{334}$ At any one time, one in every five Canadians has low back pain. ${ }^{35}$ With the enormous burden associated with musculoskeletal conditions, and these being the primary conditions that chiropractors manage, chiropractors and other providers of manual therapy have the potential to play a pivotal role in the healthcare system by providing effective, evidence-based care to the vast number of people with these conditions. ${ }^{36}$ Our results provide information about the care delivered and potential opportunities for policy-makers to promote strategies to improve quality of care by encouraging use of evidence-based guidelines among chiropractors.

\section{Strengths and limitations}

This cross-sectional study involved data collected prospectively, which eliminates potential recall bias or chart documentation errors with retrospective surveys or chart reviews. We used a method of recording patient encounters that has demonstrated reliability and validity in primary care. ${ }^{14}$ We modified and pilot tested the data collection forms to ensure that they were relevant for Ontario chiropractic practice, that instructions were clear and that the format was easy to follow. We used a validated coding system ${ }^{15} 16$ to classify reasons for encounters and diagnoses and had a quality assurance protocol to ensure reliability across coders. Moreover, we built in computer-aided error checks in the Microsoft Access database at the data entry stage to minimise error. Finally, we adjusted for clustering effects of patients presenting to the same chiropractor in the analysis.

Limitations included a $36 \%$ response rate, whereby there is the potential for selection bias. This response rate is higher than achieved in the BEACH study in 2011 $(27 \%)^{11}$ and the COAST study in $2013(33 \%){ }^{8}$ The coding of reasons for encounter and diagnoses required judgement from the coder; however, we minimised this subjectivity by using an established coding system ${ }^{15} 16$ and employing a quality assurance protocol across the two coders. The two coders were also trained on how to use the coding system and generate new terms when needed. Although we captured information that occurred during 
patient encounters, sharing of information between the chiropractor and patient may have occurred outside patient encounters (eg, collaborations and referrals). We also did not explicitly ask about exercise prescription or the provision of advice or reassurance on the encounter forms, so participating chiropractors were not prompted to record this information, rather we assumed it would be recorded by chiropractors. This may account for the low use of exercises compared with previous reports of about a quarter of patients being prescribed corrective exercises $^{6}$ and the nature of multimodal care, including education, provided by chiropractors. ${ }^{2}$

\section{CONCLUSIONS}

Our study provides the first comprehensive profiling of chiropractic clinical practice in Canada and valuable information in an under-researched area. Stakeholders of the Canadian healthcare system can use these results to ensure that chiropractic services are appropriately directed to the right patient, at the right time, by the right provider. Chiropractic education can be aligned with health conditions commonly managed by chiropractors. Future research relevant to the chiropractic profession can be guided to ensure it is directed towards the most common presentations, so as to help reduce the high societal burden associated with musculoskeletal disorders.

\section{Author affiliations}

${ }^{1}$ Research, Canadian Memorial Chiropractic College, Toronto, Ontario, Canada ${ }^{2}$ Centre for Disability Prevention and Rehabilitation, Ontario Tech University and Canadian Memorial Chiropractic College, Toronto, Ontario, Canada

${ }^{3}$ Department of Public Health Sciences, Queen's University, Kingston, Ontario, Canada

${ }^{4}$ School of Physical and Occupational Therapy, McGill University Health Centre, Montreal, Québec, Canada

${ }^{5}$ Département de chiropratique, Universite du Quebec a Trois-Rivieres, TroisRivieres, Quebec, Canada

${ }^{6}$ Research and Innovation, Canadian Memorial Chiropractic College, Toronto, Ontario, Canada

${ }^{7}$ Research, Institute for Work \& Health, Toronto, Ontario, Canada

${ }^{8}$ Department of Chiropractic, Macquarie University, Sydney, New South Wales, Australia

${ }^{9}$ School of Rehabilitation Therapy, Queen's University, Kingston, Ontario, Canada

Acknowledgements We thank the members of the Advisory Committee for their invaluable contributions to the study: Dr Robert Haig (Ontario Chiropractic Association), Dr Frances LeBlanc and Dr Robert David (Canadian Chiropractic Association) and Dr Anthony Tibbles (Canadian Memorial Chiropractic College). We thank Dr Nir Simon and Heather Owens for their assistance with recruitment of study participants; and Melanie Charity (Federation University, Australia) for her contribution to the statistical analyses. We thank the chiropractor and patient participants for their efforts in participating in this study.

Contributors Concept development (provided idea for the research): SM and SF. Design (planned the methods to generate the results): SM, SF and AB. Supervision (provided oversight, responsible for organisation and implementation, writing of the manuscript): SM, JW, DS, PJHB, AB and SF. Data collection/processing (responsible for experiments, patient management, organisation or reporting data): SM, JW, DS, PJHB, SH-J and SF. Analysis/interpretation (responsible for statistical analysis, evaluation and presentation of the results): SM, JW, DS, PJHB, AB, SH-J and SF. Literature search (performed the literature search): JW and DS. Writing (responsible for writing a substantive part of the manuscript): SM and DS. Critical review (revised manuscript for intellectual content, this does not relate to spelling and grammar checking): SM, JW, DS, PJHB, AB, SH-J and SF. Final approval and agreement for manuscript accountability: SM, JW, DS, PJHB, AB, SH-J and SF.

Funding This study was funded by the Ontario Chiropractic Association (OCA) and Queen's University. The OCA provided general advice about the design of the project, but was not involved in the collection of data, data analysis, interpretation of data or drafting of the manuscript. The funder Queen's University did not have any involvement in the project.

Competing interests SM has received an honorarium for lecturing from OCA.

Patient consent for publication Obtained.

Ethics approval The research ethics boards at the Canadian Memorial Chiropractic College (CMCC) (REB\# 1404×03) and Queen's University (REB\# 6012853) approved the study.

Provenance and peer review Not commissioned; externally peer reviewed. Data availability statement № data are available.

Open access This is an open access article distributed in accordance with the Creative Commons Attribution Non Commercial (CC BY-NC 4.0) license, which permits others to distribute, remix, adapt, build upon this work non-commercially, and license their derivative works on different terms, provided the original work is properly cited, appropriate credit is given, any changes made indicated, and the use is non-commercial. See: http://creativecommons.org/licenses/by-nc/4.0/.

\section{REFERENCES}

1. World Federation of Chiropractic. The current status of the chiropractic profession. Report to the world Health organization from the world Federation of chiropractic, 2012. Available: https://www. wfc.org/website/images/wfc/WHO_Submission-Final_Jan2013.pdf [Accessed 23 Feb 2018].

2. Beliveau PJH, Wong JJ, Sutton DA, et al. The chiropractic profession: a scoping review of utilization rates, reasons for seeking care, patient profiles, and care provided. Chiropr Man Therap 2017;25.

3. Hurwitz EL, Coulter ID, Adams AH, et al. Use of chiropractic services from 1985 through 1991 in the United States and Canada. Am J Public Health 1998;88:771-6.

4. Mior SA, Laporte A. Economic and resource status of the chiropractic profession in Ontario, Canada: a challenge or an opportunity. J Manipulative Physiol Ther 2008;31:104-14.

5. Waalen JK, Mior SA. Practice patterns of 692 Ontario chiropractors (2000-2001). J Can Chiropr Assoc 2005;49:21-31.

6. Mior SA, Soave D. Analysis and reporting of the patient management program database. Toronto: Ontario Chiropractic Association, 2011.

7. College of Chiropractors of Ontario. Protecting the public, guiding the profession, 2016. Available: https://www.cco.on.ca/wp-content/ uploads/2017/11/CCO-Annual-Report16-web.pdf [Accessed 23 Feb 2018].

8. French SD, Charity MJ, Forsdike K, et al. Chiropractic observation and analysis study (coast): providing an understanding of current chiropractic practice. Med J Aust 2013;199:687-91.

9. Britt H, Miller G, Charles J, et al. General practice activity in Australia 2010-11. general practice series no.29. Sydney: Sydney University Press, 2011.

10. Britt $\mathrm{H}$, Miller $\mathrm{G}$, Bayram $\mathrm{C}$. The quality of data on general practice - a discussion of BEACH reliability and validity. Aust Fam Physician 2007;36:36-40.

11. Britt H, Miller G, Henderson J, et al. General practice activity in Australia 2011-12. general practice series no.31. Sydney: Sydney University Press, 2012.

12. Dillman DA. Mail and Internet surveys: the tailored design method: with new Internet, visual, and mixed-mode guide. 2nd ed. Hoboken, N.J., Chichester: John Wiley \& Sons, Inc, 2007.

13. Meza RA, Angelis M, Britt H, et al. Development of sample size models for national general practice surveys. Aust $J$ Public Health 1995;19:34-40.

14. Britt $\mathrm{H}$. A measure of the validity of the International classification of primary care in the classification of reasons for encounter. Jhi 1997;6:8-12.

15. Charity MJ, French SD, Forsdike K, et al. Extending ICPC-2 plus terminology to develop a classification system specific for the study of chiropractic encounters. Chiropr Man Therap 2013;21.

16. Classification Committee World Organization of Family Doctors (WICC). ICPC-2: International classification of primary care. 2nd edn. Oxford: Oxford University Press, 1998.

17. World Health Organization. Who guidelines on basic training and safety in chiropractic. Geneva: WHO, 2005. http://www.who.int/ medicines/areas/traditional/Chiro-Guidelines.pdf 
18. Coulter ID, Hurwitz EL, Adams AH, et al. Patients using chiropractors in North America. Spine 2002;27:291-7. discussion 7-8.

19. Hurwitz EL, Chiang L-M. A comparative analysis of chiropractic and general practitioner patients in North America: findings from the joint Canada/United states survey of health, 2002-03. BMC Health Serv Res 2006;6:49.

20. Hawk C, Schneider M, Evans MW, et al. Consensus process to develop a best-practice document on the role of chiropractic care in health promotion, disease prevention, and wellness. J Manipulative Physiol Ther 2012;35:556-67.

21. Leboeuf-Yde C, Hestbæk L. Maintenance care in chiropractic - what do we know? Chiropr Osteopat 2008;16.

22. Eklund $A$, Jensen I, Lohela-Karlsson M, et al. The Nordic maintenance care program: effectiveness of chiropractic maintenance care versus symptom-guided treatment for recurrent and persistent low back pain-A pragmatic randomized controlled trial. PLoS One 2018;13:e0203029.

23. Goncalves G, Le Scanff C, Leboeuf-Yde C. Primary prevention in chiropractic practice: a systematic review. Chiropr Man Therap 2017;25.

24. Shekelle PG, Brook RH. A community-based study of the use of chiropractic services. Am J Public Health 1991;81:439-42.

25. Kopansky-Giles D, Papadopoulos C. Canadian chiropractic resources databank (CCRD): a profile of Canadian chiropractors. $J$ Can Chiropr Assoc 1997;41:155-91.

26. Bussières AE, Stewart G, Al-Zoubi F, et al. The treatment of neck Pain-Associated disorders and Whiplash-Associated disorders: a clinical practice guideline. J Manipulative Physiol Ther 2016;39:523-64.

27. Coulter I, Crawford C, Vernon $\mathrm{H}$, et al. Manipulation and mobilization for treating chronic nonspecific neck pain: a systematic review and meta-analysis for an appropriateness panel. Pain physician 2019;22:E55-70.
28. Wong JJ, Côté P, Sutton DA, et al. Clinical practice guidelines for the noninvasive management of low back pain: a systematic review by the Ontario protocol for traffic injury management (optima) collaboration. Eur J Pain 2017;21:201-16.

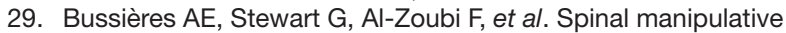
therapy and other conservative treatments for low back pain: a guideline from the Canadian chiropractic guideline initiative. $J$ Manipulative Physiol Ther 2018;41:265-93.

30. Taylor SH, Arnold ND, Biggs L, et al. A review of the literature pertaining to the efficacy, safety, educational requirements, uses and usage of mechanical adjusting devices: Part 1 of 2. J Can Chiropr Assoc 2004;48:74-108.

31. Taylor SH, Arnold ND, Biggs L, et al. A review of the literature pertaining to the efficacy, safety, educational requirements, uses and usage of mechanical adjusting devices: Part 2 of 2. J Can Chiropr Assoc 2004;48:152-61.

32. Mior S, Barnsley J, Boon $\mathrm{H}$, et al. Designing a framework for the delivery of collaborative musculoskeletal care involving chiropractors and physicians in community-based primary care. $J$ Interprof Care 2010;24:678-89.

33. Vos T, Flaxman AD, Naghavi M, et al. Years lived with disability (YLDs) for 1160 sequelae of 289 diseases and injuries 1990-2010: a systematic analysis for the global burden of disease study 2010. The Lancet 2012;380:2163-96.

34. Hartvigsen $\mathrm{J}$, Hancock $\mathrm{MJ}$, Kongsted $\mathrm{A}$, et al. What low back pain is and why we need to pay attention. The Lancet 2018;391:2356-67.

35. Lim KL, Jacobs P, Klarenbach S. A population-based analysis of healthcare utilization of persons with back disorders: results from the Canadian community health survey 2000-2001. Spine 2006;31:212-8

36. Foster NE, Anema JR, Cherkin D, et al. Prevention and treatment of low back pain: evidence, challenges, and promising directions. The Lancet 2018;391:2368-83. 